\title{
Analysis on Economic Development of the Service Area in Tonghua Normal University
}

\author{
Guangyi Liu \\ College of Business Administration \\ Tonghua Normal University \\ Tonghua, China
}

\begin{abstract}
Tonghua Normal University has the important task to cultivate a large number of talents for the economic construction and social development, serving the regional economy and the society. Making a systemic research on current conditions of schools and the regional economic development in the area is the urgent need of schools for development and social service, and exploring an effective way to serve regional economic development is the urgent need of local colleges and universities for development.
\end{abstract}

Keywords-Tonghua Normal University; regional economy; development

\section{INTRODUCTION}

Education and regional economy has a complementary and symbiotic relationship. Tonghua Normal University, like other colleges and universities, has four main functions: personnel training, scientific research, social service and cultural heritage innovation. And these four functions ultimately need to be attributed to the service society. Service society is the inevitable requirement of the diversified development of China's higher education. Relying on Colleges and universities, the development of regional economy can have the ability of sustainable development innovation, and this strength of this innovation has become an important reason for the differences of economic development between regions. It can be said, on the one hand, colleges and universities play an important supporting role in promoting regional economic and social development services, and on the other hand, regional economic development provides space for the survival and development of colleges and universities. However, the interactive mechanism between universities and regional economic development has not yet formed. Therefore, local colleges and universities should explore the compatible point with the regional economic symbiosis to achieve the symbiotic development with the regional economy.

As the only full-time college of Southeast Jilin, Tonghua Normal University which is located in Changbai Mountain takes responsibility of serving the local since it is established. It actively promotes the transformation of scientific research by gathering talent, increasing investment and cooperating school enterprise local industrial upgrading and cultural heritage innovation to provide intellectual support. And it gives full play to the advantages and characteristics of "one mountain, one city, and one ethnic, one history", forming the system of cultivating applied talents with distinctive characteristics, which has made an important contribution to the development of local economy.

\section{CURRENT ECONOMIC AND SOCIAL DEVELOPMENT OF SERVICE AREA IN TONGHUA NORMAL UNIVERSITY}

The unchanged pursuit of Tonghua Normal University that serves the regional economic and social development for many years is to focus on local social development of Tonghua and Jilin and make contribution for support. In order to meet the demand for talent changes in national and local economic society, it is necessary to cultivate advanced special talents who have enough humanistic qualities under economic new normal and those who own innovative spirits, entrepreneurial ability and dedication to apply to practice, further enhancing the school level by tapping the potential of school and the use of social resources. The leap development achieved in a relatively short period of time also reward areas, providing personnel services, the regional science and technology services, social services and other multi-domain support, which plays an irreplaceable role in the development and progress of regional economy and society.

\section{A. Focus on the Needs of Regional Economic and Social Development and Strengthen Discipline Construction}

Tonghua Normal University actively adapt to the new requirement of the regional economic and social development of the talent, vigorously develop related disciplines with the local economy, and actively explore the establishment of cross discipline, giving priority to the development of pharmacy, medicine, food science and engineering, food quality and safety, economic construction and social development needs of business administration in Tonghua and other disciplines. It will adhere to the "butt" between key construction disciplines and regional economic construction and social development, at the same time, and accelerate the development of new disciplines to make an important contribution to support the economic development of Tonghua and Jilin.

It occupies a leading position in the international study of Goguryeo history, establishing the first domestic Goguryeo Research Institute, having made important contributions to the success of Ji'an Kokuryo inscription. Tonghua Normal University has assumed the national, provincial and ministerial research projects more than 40 research monographs, essays 
published Koguryo more than and 30, and more than 400 papers published. The China Koguryo History shortlisted for the National Book Award, winning the first prize in the Jilin Provincial Government Press and awarding the excellent book in the Changbai Mountain, which creates the academic journals of Goguryeo and Northeast Ethnic Studies. At present, the university of Goguryeo research results and research platform have become an important part of our country for the Koguryo issue.

Since 2000, Tonghua Normal University has opened Manchu paper-cut, embroidery, straw and other folk art courses. Facing the society, it started Manchu folk paper-cut training class, and also hired the Manchu paper-cut inheritors of Ni Youzhi, Hou Yumei and Wan Limei as a straw artist to the college site guidance, training for the Manchu intangible cultural heritage skills. In 2003, it established the country's first Manchu Folk Art Museum, 28 techniques included in the Jilin province intangible cultural heritage list, Changbai Mountain Manchu paper-cut being in the United Nations human representative list of intangible cultural heritage. "Manchu paper-cut", "Manchu pillow top embroidery", "hickory collage skills" of school were on behalf of Jilin province to participate in Shanghai and 2015 "Design in Shanghai" exhibition, praised by audiences all over the world.

\section{B. Provide High-quality Research Services and Leading the Region's Scientific and Technological Progress and Industrial Development}

Scientific research is not only a strong school road, but also the key to serving the local university. With a good level of scientific research and technological innovation, Tonghua Normal University follows the pace of regional economic development and serves local economic and social development to provide a lot of valuable technical support for the regional construction in Tonghua area in recent years. Our university teachers' participation in regional economic and social development mainly in the following ways: actively participating in local economic construction and services through the application of scientific research project; strengthening the combination of direct service for local economy; participating in the "double" for local economic and social development services; conducting consulting services, directly participating in regional projects, carry out academic exchange activities and so on.

It has signed a cooperation agreement with Tonghua Wantong Pharmacy Group, Xiuzheng Pharmacy Group, Yusheng Pharmacy Group and other enterprises and institutions, having established Wantong studio and carrying out in-depth cooperation with them, so that once approved Changbai Mountain Provincial Key Laboratory of medicinal plant research, provincial innovation experimentation area of pharmaceutical and food professionals training model integrating the local pillar industry chain, and 38 cooperative projects with enterprises to carry out scientific research. With the faster pace of construction of national medical high tech Zone in Tonghua and increasingly growing demand of innovative talents, the university actively implements the transformation of development strategy, focusing on the pharmaceutical and health industry chain integration, pharmacy, medicine, food science and engineering, food quality and safety, product design, marketing, applied chemistry, biotechnology and other majors to construct a professional medical health industry cluster. It also carries out strategic cooperation with the Tonghua municipal government to integrate quality education resources of Tonghua City Health School and jointly found the Applied Technology School of Tonghua Normal University, building a vocational training overpass from secondary vocational school to higher vocational college to step on the road of transformation and development.

\section{Give Full Play to the Advantages and Characteristics to Provide High-qQuality Personnel Services for Regional Development}

Education is the foundation of the school. Developing with education and improving the quality of personnel training are important means of Tonghua Normal University to serve local economic and social development.

The university prepares a large number of outstanding graduates who can root in grass-roots and dedicate themselves to work, well received by the employers and the communities. According to incomplete statistics, nearly half of the key staffs of the basic education in Tonghua and Baishan region are graduates of our school. Based on the job, they can bear hardship, dedicate to work and teach well, some of them becoming mayor, deputy mayor, directors of Education Bureau, headmaster, famous provincial teachers and excellent teachers. Over the years the school transports a large number of professional and technical personnel and management personnel for industries and enterprises in Tonghua, and some graduates became chairman, general manager. Graduates of our school are spread across the Tonghua pharmaceutical companies as middle management cadres and senior technical personnel, making great efforts for the local economic development and industrial progress and provide talent and the economic construction and social development for the Tonghua area, even for Jilin province.

\section{Lead Advanced Culture to Provide High-Quality Cultural Services for the Development of Area and City}

Local colleges and universities exist in a specific regional environment and have to bear the mission of community participation. Since its establishment, Tonghua Normal University has played an important role in serving the community construction of local colleges and universities, and made full use of local university cultural resources to serve the urban civilization and harmonious development of Tonghua. Our school teachers and students can be easily found in the Tonghua area culture and art stages, for example Shanying Choir who offers elegant performances to the people of Tonghua every year. Efforts are made to increase the influence and reputation of Tonghua City by winning a number of international and domestic competition awards. Academy of Fine Arts designed public welfare comics for the Tonghua Civil Affairs Bureau, making contributions to the development of public welfare undertakings in Tonghua. Tonghua Normal University stadium provides a high level of service for the community, and undertakes various sports events in the region 
every year, so that we can serve for the society to cultural construction and city planning.

\section{DEFICIENCIES OF TONGHUA NORMAL UNIVERSITY IN THE ECONOMIC AND SOCIAL DEVELOPMENT PROCESS OF THE SERVICE AREA}

With the discipline construction, today's Tonghua Normal University has entered for the local economic and social development to improve the quality of personnel training as the core, deepen the educational reform, and comprehensively promote the new development stage of school work. However, in the rapid development of our school and construction of investment in Tonghua, we calmly see own shortcomings that is when making a comprehensive survey of the four major functions of universities, social service is the weakness of a common university. As far as our university is concerned, the development of the subject is unbalanced, the discipline advantage not obvious, the degree of talent training and social demand not high, and the scientific research results and the enterprise needs have gaps and so on.

\section{A. Unbalanced Discipline Development and Less Obvious Discipline Characteristic Superiority Cause Limitations in the Economic Development of the Service Area}

Our university is facing the situation to revitalize the northeast old industrial base, construct Jilin Tonghua international inland port, plan "Changjitu" strategic development and Tongdan economy and other multiple strategic opportunities. But at the same time, opportunities and challenges exist side by side, revealing the shortcomings of inconspicuous advantages of the discipline characteristics and unequal discipline development, which limits our school in the local economic construction and social services.

\section{B. Professional Structural Adjustment, Optimization Work Still Needs to Be Strengthened and the Quality of Personnel Training Needs to Be Further Improved}

1) Our professional structure is relatively stable, but there are still disadvantages such as less majors related to social and economic development in Tonghua, unset much needed majors, inconspicuous characteristics of many majors, inaccurate professional positioning, single personnel training mode and imperfect compound construction mechanism.

2) For a long time, the practice of personnel training link is very weak in the university and can not keep up with requirements of the society and enterprises under new situation.

.3) What the university itself requires from students is mainly ability requirements instead of considering the demand of the employing unit, which causes low docking degree between enterprises and trained talents who are weak in the capability of practice with high level of theory and application, still having a large gap in mutual communication with them.

4) The university should further improve graduates information feedback and collection mechanisms, further listen to talent training ideas from society and enterprises, and strengthen communication with the employer to actively cultivate the talents for regional development.

\section{The Reason that Science and Technology Achievements Transformation Ability Is Not Strong}

First is the small cooperation scale among the university, society and enterprises, having low surface cooperate level and low level of organizational degree. Second, it lacks of a unified organization and a closer cooperation platform and many scientific and technological achievements have not translated into productive forces. Some research projects of teachers and researchers are only for assessing the title and publishing papers, so it is still so far away to realize the transformation of scientific and technological achievements that it can not be effectively translated into local economic and social development services.

\section{CONCLUSION}

Practice has proved that developing a benign mutual relationship is the only way for the common development of colleges and universities and regional society. As a local university, it should base on local conditions, give full play to the advantages of professional disciplines, form its own characteristics, and actively promote the education reform and innovation to better achieve the functions of social services and get out of a distinctive feature of the development of the road, looking forward to the future. Tonghua Normal University will continue to adhere to the strategy of "quality of university, talent of university, scientific research of university, and characteristics of university" to join the local economic and social development with a more positive attitude. Taking the service for local area as a breakthrough point, it will allroundly enhance capabilities of supporting transformation upgrading, technological progress and social management innovation. Take quickening the connotation of the development as the theme and reforming and making innovations as the motive force to keep a foothold in Tonghua, face Jilin Province and serve for the whole nation, striving to cultivate high-quality talents for the needs of the local economic and social development, fully playing to the regional economic and social development of local universities, for a re-created brilliance in Tonghua region and Jilin Province.

\section{REFERENCES}

[1] Cai Juan. On the School-Running Characterics Construction of Local Colleges and Schools in China and the Deep Transformation of Local Service Strategy [J]; Education and Economy; 2010(3):

[2] Pu Xiaomei, Cheng Zibiao, Xiang Yanyan. Study on Local Universities Serving the Local Economic and Cultural Construction - A Case of Sichuan University of Arts and Sciences [J]. Journal of Economic Research, 2013 (7).

[3] Luo Yan. The Reform of Personnel Training Mode in View of the Employment of College Students [J]. China Higher Education, 2010 (9). 